\title{
Mapping spatial disparity of canal water distribution under irrigated cropping environment using satellite imageries
}

\author{
S. A. Rizvi $\cdot$ M. Latif $\cdot$ S. Ahmad
}

Received: 29 March 2011/Revised: 1 August 2011/Accepted: 30 November 2011/Published online: 25 April 2012

(C) CEERS, IAU 2012

\begin{abstract}
In this study, a great variation in crop yield, which affects the socio-economic and physical environment of the area, is observed along the irrigation channels in Pakistan. This is mainly due to inequitable distribution of canal water causing spatial variations along the system. Assessing the performance of irrigation system can help to find any disparity which should be rectified to achieve the desired objectives of irrigation. Due to lack of real-time data, performance of an irrigation system cannot be readily determined particularly in developing countries. Remote sensing and geographic information system are the best tools to overcome this difficulty. Normalized difference vegetation index indirectly indicates the presence of water in plants. Biomass production and evapotranspiration are crucial indicators for describing the spatial variation of irrigation water. In this study, infrared bands of the Advanced Spaceborne Thermal Emission and Reflection Radiometer sensor were used to determine surface temperatures and various components of the energy balance equation. The spatial disparity in evapotranspiration was found from head to tail of the system. Classification of evapotranspiration into different groups revealed that the area under higher evapotranspiration range is more at the head of the system than its tail, which indicates that more canal water is supplied at the head of the system. These results clearly testify the disparity of canal water distribution along the system leading to reduced income and environmental degradation of the downstream water users.
\end{abstract}

S. A. Rizvi $(\bowtie) \cdot$ M. Latif $\cdot$ S. Ahmad

CEWRE, University of Engineering and Technology,

Lahore, Pakisthan

e-mail: engrsultan68@yahoo.com
Keywords Aster images - Energy balance . Evapotranspiration - Normalized difference vegetation index $\cdot$ Solar radiation

\section{Introduction}

Water management is a survival issue of mankind especially in areas where rainfall is sparse and scanty such as in arid and semiarid regions of Pakistan. About $40 \%$ of world's food requirement is currently contributed by only $17 \%$ of irrigated lands (Abdullah 2006). Pakistan is an agricultural country and its irrigation system is the largest contiguous gravity flow network of the world contributing around $90 \%$ of total food production in the country. But presently, the irrigated agriculture is facing serious threats of water scarcity, degradation of land and water resources, low water productivity, unequal distribution and access to irrigation water.

A significant decrease in yield of crops is observed from upper to lower reaches along the irrigation canals in Pakistan (Latif 2007). This is mainly due to unequal distribution of canal water and degradation of lands especially at the tail ends of the irrigation channels. Efforts for improving regional water management are often thwarted because of dearth in reliable and consistent information. Main constraints in collection of data are large overhead expenditures, unreasonable time lags, and quality concern. Due to lack of basic understanding of the spatial and temporal variability of hydrologic parameters, water productivity assessment and enhancement have become a major challenge in the country that is the key to enhance agricultural production and improve the social and physical environment below the head of irrigation system. Availability of timely and precise information on the area and 
growth of the crops are the basic elements for sound agricultural planning, development and policy formulation. Regular collection and analysis of data are often required to devise a systematic and comprehensive water management approach, which involves heavy expenses. Furthermore, it is difficult to replicate or even continue for longer time periods. Data to quantify the irrigation performance indicators such as equity, adequacy, reliability and water productivity are rarely collected. To make a performance-oriented approach effective, it is necessary to apply new techniques and approaches to existing management practices.

Satellite data provide continuous information about a number of features including agricultural and hydrological conditions on surface of the Earth. Remote sensing provides spatial and temporal information on irrigated cropped area, cropping pattern, type of crop, biomass development, crop yield, evapotranspiration, salinity, water-logging and many other parameters. Ultimately it helps in irrigation performance characterization with regard to location on the irrigation network (Bastiaanssen 2000). Improved irrigation management and decision-making call for adoption of new tools such as remote sensing (RS) and geographic information system (GIS) to provide necessary spatial and temporal information on different sub-systems and for different user groups. These techniques help in integration of remotely sensed and ground data in evaluating the performance of an irrigation system, diagnosing the water supply inequalities and help in improving water use and its management. Based on remotely sensed data there are many indicators such as normalized difference vegetation index (NDVI), biomass, evapotranspiration (ET), soil moisture which describe the performance of an irrigation system. Biomass production in response to available water is the ultimate indicator for describing crop response to irrigation water. In this study, the satellite data in the thermal infrared portion of the spectral region were utilized to find out the surface heat flux from which spatial variation in ET was estimated. Surface energy balance approach has been used to describe spatial variability in canal water distribution represented by ET and land wetness conditions of the soil. Main objective of this study is to formulate a quick and efficient methodology to assess the performance of an irrigation system without engaging a lot of manpower for data collection. The proposed objective of the study has been achieved by demonstrating the use of ASTER (Advanced Spaceborne Thermal Emission and Reflection Radiometer) data in assessment of the spatial variability of irrigation water distribution by estimating evapotranspiration over the irrigated area.

Precise and dependable estimation of evapotranspiration resulting from transfer of energy and mass between land and atmosphere plays an important role in monitoring of water resources and for assessing the performance of an irrigation system. The sun energy comprising sensible and latent heat fluxes arriving at land surface considerably influences the climate from narrow to large scales. Generally, lower temperatures indicate the presence of considerable moisture, because a major portion of incoming energy goes into latent heat or evaporation while hotter temperatures indicate that most of the incoming energy goes into sensible or convective heating of the atmosphere (Schmugge et al. 1998).

Evapotranspiration (ET) from all types of vegetation, i.e., crops, forests, weeds, and evaporation (E) from bare soils and open water bodies such as rivers, large irrigation canals, and ponds etc. make an essential boundary condition for regional scale hydrological modeling (Droogers and Bastiaanssen 2002). The estimation of evapotranspiration (ET) using the traditional methods can only be used for local environment if the climatic data are available. However, the point estimates of ET cannot be applied at regional level due to variable conditions of soil, water, climate, biological as well as physical properties of landscape such as surface albedo, emissivity and the crop. The Remote sensing and GIS techniques are more accurate and trustworthy means of mapping spatial distribution of evaporation $(E)$ or evapotranspiration (ET) at regional scale. Main advantage of this technique is that water used by soil-water-plant system can be estimated directly without going into complexity of hydrological process. Vegetation density and the surface albedo are estimated by using very near infrared (VNIR) and short wave infrared (SWIR) bands of the ASTER imageries, whereas the surface temperature is estimated from thermal infrared bands. Gillespie et al. (1998) concluded that surface temperature is independent of wavelength and it can be estimated from even a single band of radiance data if atmospheric characteristics and emissivity are specified. Das and Iqbal (1987) used a simplified approach to compute spectral atmospheric radiation. The other variables of energy balance equations have to be measured at land surface, estimated or modeled (Moran and Jackson 1991).

Carlson et al. (1981) and Taconet et al. (1986) used onedimensional boundary layer model to estimate evaporation using thermal infrared and ground-based weather data. Gurney and Hall (1983) presented a method which requires remotely sensed surface albedo in addition to surface temperature and meteorological data for estimation of daily evaporation. Price (1982) also proposed an analytical model which uses remotely sensed surface temperature and reflectance in combination with meteorological data for estimation of daily evaporation rates employing energy balance equation. Similarly, Jackson (1985) proposed similar evaluation of energy balance over agricultural areas by combining the remotely sensed energy partitioned into its components. Bastiaanssen et al. (1998) developed an energy balance algorithm for land (SEBAL) to calculate energy partitioned into its components at the regional scale. Norman et al. (1995) used a two source procedure known as two-source energy balance (TSEB) for estimation of evapotranspiration. Many 
other scientists have also tried to employ the energy balance approach for estimation of evapotranspiration. Such efforts are still ongoing to refine the procedure for estimation of land surface fluxes using satellite data. This manuscript presents the assessment of spatial variability of irrigation water distribution by estimating the various components of energy balance equation using remotely sensed data of ASTER. ASTER images comprising two sets of level-1A data for 4th March 2006 and 5th April 2006 were acquired for the irrigation command area of Main Branch Lower Canal in Central Punjab, Pakistan.

\section{Materials and methods}

Location of the study area

The study area is located between $73^{\circ} 34^{\prime} \mathrm{E} 31^{\circ} 17^{\prime} \mathrm{N}$ and $74^{\circ} 32^{\prime} \mathrm{E} 30^{\circ} 53^{\prime} \mathrm{N}$ and it lies along the main branch lower (MBL) canal system in Central Punjab Pakistan. This system formerly known as the Upper Bari Doab Canal, off takes from Bambanwala Ravi Bedian Depalpur (BRBD) Canal and irrigates part of district Kasur as shown in Fig. 1. This system is perennial with water allowance of $0.24 \mathrm{~m}^{3} \mathrm{~s}^{-1}$ per 1,000 ha ( $3.45 \mathrm{ft}^{3} \mathrm{~s}^{-1}$ per 1,000 acres). Discharge capacity of the canal is $48.53 \mathrm{~m}^{3} \mathrm{~s}^{-1}\left(1,714 \mathrm{ft}^{3} \mathrm{~s}^{-1}\right)$, commands 0.134 million ha (0.332 million acres) of area. In this system three channels namely Athailpur, Cheena and Zafarke were selected which are located at the head, middle and tail of the main canal, respectively. Major winter crop is wheat (November-May)

and rice is the main summer crop (June-October). Vegetables are grown round the year. Perennial crops encompass sugarcane, orchards and fodder. This area receives rainfall ranging from 750 to $1,000 \mathrm{~mm}$ annually and most of which falls in summer months (June-September). Further details of the study are described in Latif and Ahmad (2007).

Data and methodology

Two sets of ASTER images comprising level-1A data each on 4th March and 5th April 2006 at 5:54 GMT (10:54 local time) (centered at $31.4^{\circ} \mathrm{N}, 74.4^{\circ} \mathrm{E}$ and $30.9^{\circ} \mathrm{N}, 74.2^{\circ} \mathrm{E}$, respectively) were acquired. ASTER is a multi-spectral instrument (Yamaguchi et al. 1998). Complete description of properties of Aster image is given below:

Total number of spectral bands

Type of bands in Aster image

Spatial resolutions of VNIR

Spatial resolutions of SWIR

Spatial resolutions of TIR

Spacecraft altitude

Swath width

Output signals for VNIR and SWIR

Output signals for TIR

Edge to edge field of view

14
VNIR, SWIR and TIR
$15 \mathrm{~m}$
$30 \mathrm{~m}$
$90 \mathrm{~m}$
$705 \mathrm{~km}$
$60 \mathrm{~km}$
$8 \mathrm{bits}$
16 bits
$4.9^{\circ}$ for all bands

Various packages used for image analysis such as ERDAS, PCI, ILWIS, ENVI have standard import options

Fig. 1 Location of study area

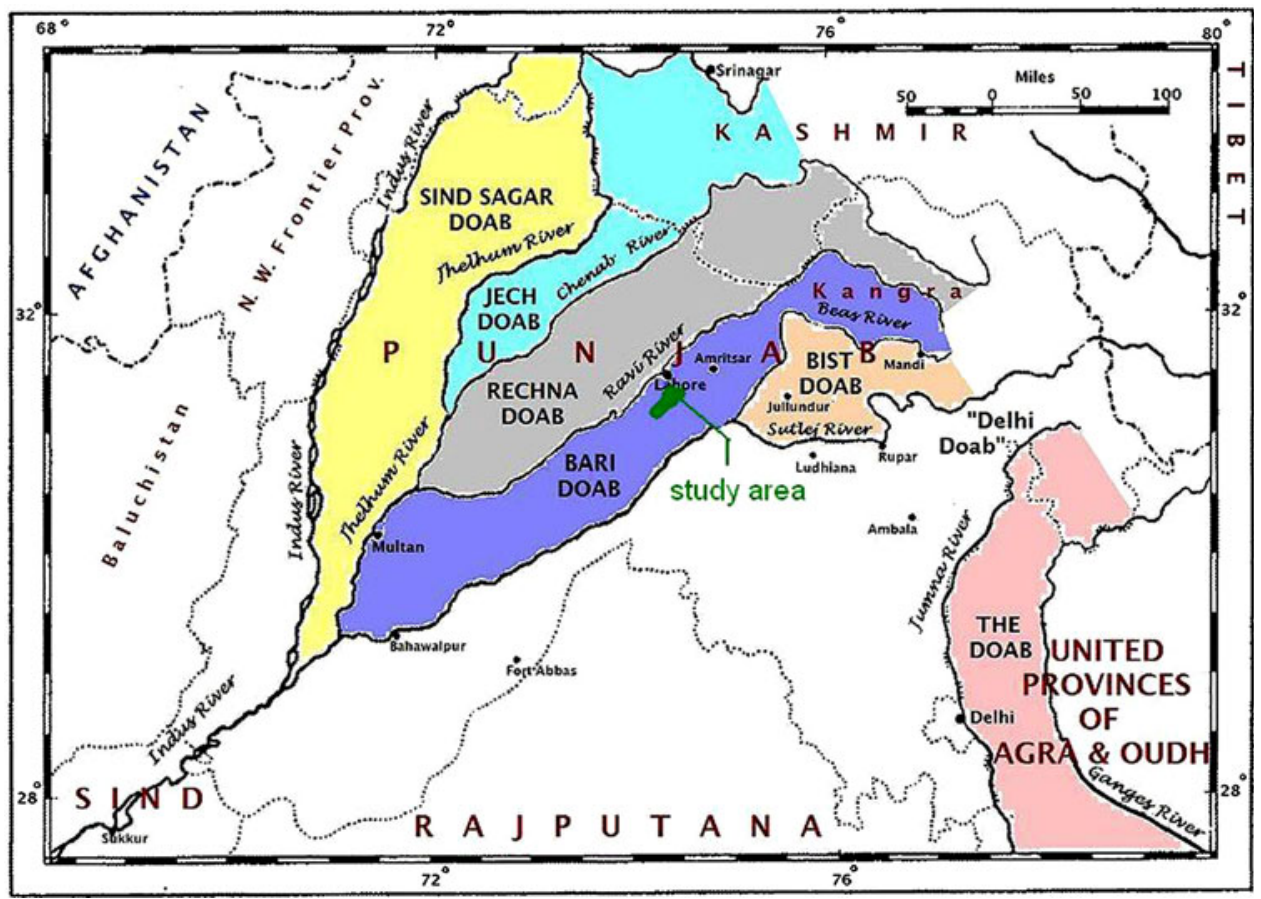


Table 1 Weather conditions on the days of image acquisition (Julian day 63 and 95)

\begin{tabular}{llll}
\hline Parameter & Unit & $\begin{array}{l}\text { Values on } \\
\text { Julian day 63 } \\
\text { (March 4 2006) }\end{array}$ & $\begin{array}{l}\text { Values on } \\
\text { Julian day 95 } \\
\text { (April 5 2006) }\end{array}$ \\
\hline Relative humidity & Percent & 47.0 & 25.0 \\
$\begin{array}{l}\text { Air temperature } \\
\text { Wind speed }\end{array}$ & ${ }^{\circ} \mathrm{C}$ & 25.0 & 32.7 \\
$\begin{array}{l}\text { Crop } \\
\text { evapotranspiration }\end{array}$ & $\mathrm{mm} \mathrm{day}^{-1}$ & 2.5 & 2.5 \\
$\begin{array}{l}\text { Reference } \\
\text { evapotranspiration }\end{array}$ & $\mathrm{mm} \mathrm{day}^{-1}$ & 3.60 & 2.80 \\
$\begin{array}{l}\text { Pan evaporation } \\
\text { mm day }\end{array}$ & & 3.80 & 5.00 \\
\hline
\end{tabular}

for the above type of files. ERDAS Imagine software developed by Earth Resource Data Analysis System Inc., Atlanta, GA, combines remote sensing and GIS capabilities, enabling to create geospatial data (http://www.erdas. com/products/ERDASIMAGINE/ERDASIMAGINE/Details. aspx). The spatial modeler of ERDAS Imagine was used for image analysis and to perform pixel-by-pixel calculations. In the first step, images were checked for cloud cover. The cloud cover visible in the extreme center left of the two mosaicked images was less than $10 \%$. Then original coding of 16-bit TIR bands was re-scaled to 8-bit to combine with VNIR and SWIR bands into one file. Radiometric correction was also applied to convert the data into radiance for the study site. Details of this procedure can be found in Tomanian et al. (2004). All the images were geo-referenced with the help of Google Earth and to compensate for small deviations geo-referencing was validated manually with the help of GPS. At the time of year when the images were taken, the area was mainly covered by wheat and fodder crops. Since the spatial resolution of TIR band was $90 \mathrm{~m}$ and SWIR band was $30 \mathrm{~m}$, their spatial resolutions were enhanced $15 \mathrm{~m}$ to match with VNIR bands. The Aster images contains 5 thermal bands, but here for this study only band 13 was used for generating image for surface temperature. The reason behind this simple one-band approach is that a temperature/emissivity separation is available at higher level in ASTER product (Gillespie et al. 1996). The climatic data were taken from the nearest meteorological station of Lahore (Table 1).

As suggested by Iqbal (1983) standard radiation relations were employed to estimate the solar parameters. The sinusoidal and linear interpolations were used to obtain the instantaneous values of air temperature $\left(T_{\mathrm{a}}\right)$ and relative humidity $(\mathrm{RH})$ obtained from the maximum and minimum values of $T_{\mathrm{a}}$ and $\mathrm{RH}$ on that day.

\section{Estimation of irrigated areas}

Irrigated areas are mostly indicated by vegetation and researchers had established various types of vegetation indices. The indices are extremely sensitive to crop vigor and moisture stress. Among these several vegetation indices, normalized difference vegetation index (NDVI) which is the ratio of difference in infrared and red bands to their sum of reflectance is widely used for estimation of irrigated areas (Akbari et al. 2007). Hence in this study NDVI was used which is a function of green leaf area, biomass and reflectiveness of the crop vigor.

\section{Evapotranspiration}

Land surface evapotranspiration (ET) is the transfer of moisture from wet soil (evaporation, $E$ ) and from surface of plant (transpiration, $T$ ) into the atmosphere. The ET is primarily controlled by the energy and heat exchange at land surface. Surface energy balance algorithm (Bastiaanssen et al. 1998) was employed to estimate evapotranspiration. The combination of remotely sensed data with ground data were used to map the reference ET over the study area. These calculations were performed pixel by pixel using the spatial module of the software package, ERDAS. Some parameters of energy balance equation such as surface albedo, surface temperature and thermal infrared emissivity were estimated from remote sensing data which were then used in computation with reflected short wave and emitted long wave radiation. Net radiation absorbed at the surface of each pixel was found from a combination of short- and long-wave radiations. The net radiation was partitioned into latent-, sensible- and soil heat fluxes. The latent heat flux (LE) is written as:

$\mathrm{LE}=R_{\mathrm{n}}-G_{o}-H$

where $R_{\mathrm{n}}$ is net radiation, $G_{o}$ is soil heat flux and $H$ is sensible heat flux.

Net radiation $\left(R_{\mathrm{n}}\right)$

Thermal radiation at the land surface comprises four spectral radiant fluxes: the incoming short wave $(0.14$ $4 \mu \mathrm{m})$ radiation emitted from the sun $\left(R_{\mathrm{S}} \downarrow\right)$, the portion of this incoming radiation reflected back from the surface $\left(R_{\mathrm{s}} \uparrow\right)$, the incoming long wave $(>4 \mu \mathrm{m})$ radiation from the atmosphere $\left(R_{\mathrm{L}} \downarrow\right)$, and the amount of long wave radiation emitted from the surface $\left(R_{\mathrm{L}} \uparrow\right)$. Thus the net radiation is balanced as:

$R_{\mathrm{n}}=R_{\mathrm{s} \downarrow}-R_{\mathrm{s} \uparrow}+R_{\mathrm{L} \downarrow}-R_{\mathrm{L} \uparrow}$.

The incoming radiations are quite independent of earth's condition (e.g., bare soil or vegetation) while the outgoing radiations are entirely dependent on the earth's conditions. Jackson (1985) argued that incoming radiation $\left(R_{\mathrm{s}} \downarrow\right.$ and $\left.R_{\mathrm{L}} \downarrow\right)$ can be recorded with conventional ground instruments (e.g., pyranometer) and extrapolated some 
distance away from the measuring point and that the outgoing radiations can be obtained from multi-spectral satellite imageries. In absence of any such instrument at site, recorded data for $R_{\mathrm{s}} \downarrow$ was taken and the surface albedo $\alpha$ which is similar to surface reflectance was calculated by applying the following equation which is based on the earlier work of Chavez (1996) and Lu et al. (2002) as presented by Milder (2008).

$\Re=\frac{\pi \times\left(L_{\text {sat }}-L_{\text {haze }}\right) \times d^{2}}{E_{\text {sun } \lambda}\left[\left(\cos \theta_{s}\right)^{2}\right]}$

where $\Re=$ surface reflectance, $L_{\mathrm{sat}}=$ at-sensor radiance (raw images were converted into radiance while importing into the software), $L_{\text {haze }}=$ estimate of upwelling scattered path radiance due to atmospheric haze and aerosols. Since there was no haze present so it was ignored. $D=$ earthsun distance in $\mathrm{km}$, calculated by using the following equation:

$$
\begin{aligned}
d= & (1-0.01672 \times \operatorname{Cos}(\operatorname{Radians}(0.9856 \\
& \times(\text { Julian day }-4))))
\end{aligned}
$$

$E_{\text {sun } \lambda}=$ a constant that is different for each Aster band as listed below (Smith 2007). where $\varepsilon_{\mathrm{S}}$ is surface emissivity and $T_{\mathrm{S}}$ is surface temperature $(\mathrm{K})$. The emissivity $\left(\varepsilon_{\mathrm{s}}\right)$ was obtained from following logarithmic relation reported by Van de Griend and Owe (1993):

$\varepsilon_{\mathrm{s}}=1.0094+0.047 \times \ln (\mathrm{NDVI})$.

The instantaneous net radiation at earth's surface is the total of all incoming and outgoing radiations that can be written as:

$R_{\mathrm{n}}=(1-\alpha) R_{\mathrm{s} \downarrow}+\varepsilon_{\mathrm{a}} \sigma T_{\mathrm{a}}^{4}-\varepsilon_{\mathrm{s}} \sigma T_{\mathrm{s}}^{4}$.

All the terms are defined above.

Soil heat flux

The soil heat flux, $G_{o}$ was computed with the following empirical fraction proposed by Bastiaanssen (2000).

$$
\begin{aligned}
G_{o}= & R_{\mathrm{n}}\left(\frac{T_{\mathrm{s}}}{\alpha}\right) \times\left(0.0038 \alpha+0.0074 \alpha^{2}\right) \\
& \times\left(1-0.98 \mathrm{NDVI}^{4}\right)
\end{aligned}
$$

\begin{tabular}{llllllllll}
\hline ASTER band & B1 & B2 & B3 N & B4 & B5 & B6 & B7 & B8 & B9 \\
$E_{\text {sun } \lambda}$ & $1,845.99$ & $1,555.74$ & $1,119.47$ & 231.25 & 79.81 & 74.99 & 68.66 & 59.74 & 56.92 \\
\hline
\end{tabular}

$\theta_{\mathrm{s}}=$ solar zenith angle $=90^{\circ}-$ solar elevation angle which was obtained from the ASTER metadata file in the "Solar_Elevation_Angle" section that were read as $47.20^{\circ} \mathrm{N}, 47.76^{\circ} \mathrm{S}$ for 4 th March 2006 and $59.47^{\circ} \mathrm{N}$, $59.96^{\circ} \mathrm{S}$ for 5th April 2006, respectively).

The portion of solar radiation absorbed at the earth surface can be written as:

$R_{\mathrm{abs}}=(1-\alpha) R_{\mathrm{s}} \downarrow$

where $\alpha$ is surface albedo and is similar to surface reflectance calculated using Eq. 3.

The incoming long wave radiation $\left(R_{\mathrm{L}} \downarrow\right)$ was calculated from the available data of air temperature and vapor pressure applying following relationship developed by Brutsaert (1975).

$R_{\mathrm{L} \downarrow}=\varepsilon_{\mathrm{a}} \sigma T_{\mathrm{a}}^{4}$

where $\varepsilon_{\mathrm{a}}=$ atmospheric emissivity $\left[\varepsilon_{\mathrm{a}}=1.24(\mathrm{ed} / \mathrm{Ta}) 1 / 7\right]$, $\sigma=$ Stefan-Boltzman's constant $\left(5.67 \times 10^{-8} \mathrm{w} \mathrm{m}^{-2} \mathrm{~K}^{-4}\right)$, $T_{\mathrm{a}}=$ air temperature $(\mathrm{K})$, ed $=$ vapor pressure deficit (mbar).

The outgoing long wave radiation $\left(R_{\mathrm{L}} \uparrow\right)$ was estimated from thermal band of the images ignoring reflected sky radiation with the help of the following relationship:

$R_{\mathrm{L} \uparrow}=\varepsilon_{\mathrm{s}} \sigma T_{\mathrm{s}}^{4}$
Sensible heat flux

The sensible heat flux, $H$ is the most difficult term to estimate due to its dependence on aerodynamic resistance. It is commonly expressed as a function of $T_{\mathrm{S}}$ and $T_{\mathrm{a}}$ as:

$H=\frac{\rho C_{p}\left(T_{\mathrm{s}}-T_{\mathrm{a}}\right)}{r_{\mathrm{a}}}$

where $\rho=$ dry air density $\left(\mathrm{kg} \mathrm{m}^{-3}\right), C_{p}=$ specific heat capacity of air $\left(\mathrm{J} \mathrm{kg}^{-1}{ }^{\circ} \mathrm{C}^{-1}\right)$ and $r_{\mathrm{a}}$ is the aerodynamic resistance to heat transport $\left(\mathrm{s} \mathrm{m}^{-1}\right)$. The aerodynamic resistance is expressed in terms of surface roughness, wind speed and displacement height. It is defined as transfer coefficient for heat transport. Due to complexity in determination of $r_{\mathrm{a}}$, it is usually determined empirically (Schmugge et al. 1998). Amongst various semi-empirical relations, the expression reported by Carlson et al. (1995) is the simplest but it underestimates $H$ over the urban areas (asphalt, concrete or building, etc.) where vegetation index is very low and consequently overestimates LE. Therefore, to avoid complexity in estimation of $H$, a semi-empirical generalized expression for aerodynamic resistance proposed by Thom and Oliver (1977) was used to estimate $r_{\mathrm{a}}$ :

$r_{\mathrm{a}}=\frac{4.72\left\{\ln \left(z / z_{o}\right)\right\}}{(1+0.54 u)}$ 
where $z=$ reference height of wind speed measurement $(m), z_{\mathrm{o}}=$ surface roughness length for momentum (m) and $u=$ wind speed $\left(\mathrm{m} \mathrm{s}^{-1}\right)$.

The values of $z_{\mathrm{o}}$ were estimated using the following relationship proposed by Moran (1990):

$z_{o}=\exp (0.1021+0.1484 \times \mathrm{LAI})$

where LAI is the leaf area index and it is the ratio of near infra red (NIR) to red band.

Estimation of daily evapotranspiration

Daily evapotranspiration, ET can be estimated from remotely sensed data indirectly by employing energy balance approach. As discussed above the component heat fluxes are related to each other as given in Eq. 1 and latent heat flux (LE) is related to evaporative fraction (EF). The latent heat of vaporization (LE) was calculated by Eq. 1 . The values so obtained were the instantaneous values of LE. These instantaneous values of LE calculated by Eq. 1 and the instantaneous flux values determined in the previous sections for the satellite overpass time can be converted into daily and average monthly values of evaporative fraction (EF). Brutsaert and Chen (1996) and Shuttleworth et al. (1989) reported that the instantaneous evaporative fraction, the ratio of latent heat flux to the sum of latent and sensible heat fluxes are similar to the 24-h evaporative fraction and is expressed as:

$\mathrm{EF}=\mathrm{LE} /(\mathrm{LE}+H)=\mathrm{LE} /\left(R_{\mathrm{n}}-G_{o}\right)$.

The values of EF calculated from the above equation were used to compute actual 24-h evaporation from the instantaneous latent heat flux. An instantaneous estimate of fluxes as given above and the product of $\mathrm{EF}$ and net radiation $\left(R_{\mathrm{n}}\right)$ provided the daily ET when the day time average
$\left(R_{\mathrm{n}}+G_{o}\right)$ was estimated by ignoring the soil heat flux $\left(G_{o}\right)$ because the soil heat flux $\left(G_{o}\right)$ can be ignored on a daily basis as there are substantial scientific evidences that $\mathrm{EF}=\mathrm{EF}_{24}$ (Shuttleworth et al. 1989; Crago 1996). Several studies have reported that this technique gives reasonably good results with differences in daily ET less than $1 \mathrm{~mm} \mathrm{day}^{-1}$ (Hall et al. 1992; Jackson et al. 1983; Kustas et al. 1994; Sugita and Brutsaert $1991)$. The daily evaporation $\left(E_{24}\right)$ thus reduced to:

$E_{24}=\mathrm{EF} \times R_{\mathrm{n}, 24}$

where $E_{24}$ is evaporation from all surfaces (i.e., vegetation, soil, water, etc.), $R_{\mathrm{n}, 24}=24 \mathrm{~h}$ net radiation (watt $\mathrm{m}^{-2}$ ).

\section{Results and discussion}

Two sets of ASTER images acquired on 4th March and 5th April 2006 were used for assessment of spatial variability of canal water distribution. Images of evaporative fraction (EF) were developed by formulating different models to apply the energy balance approach after processing the ASTER images. The results are presented in Figs. 2 and 3, respectively, for both the dates. It is apparent from these figures that the agricultural fields situated near the main canal show higher values of EF compared to the fields situated at lower reaches of the main canal. Similarly, the agricultural fields situated at the heads of the secondary canals locally called distributaries (i.e., Athailpur, Cheena and Zafarke) show higher evaporative fraction as compared to the fields located at middle and tail reaches of these channels.

There is comparatively significant difference in the overall evaporative fractions along these secondary channels as a whole considering the head, middle and tail of the main canal as well. In Figs. 2 and 3 more reflectance can be
Fig. 2 Spatial variation of evaporative fraction $\mathrm{EF}(\%)$, on 4th March 2006
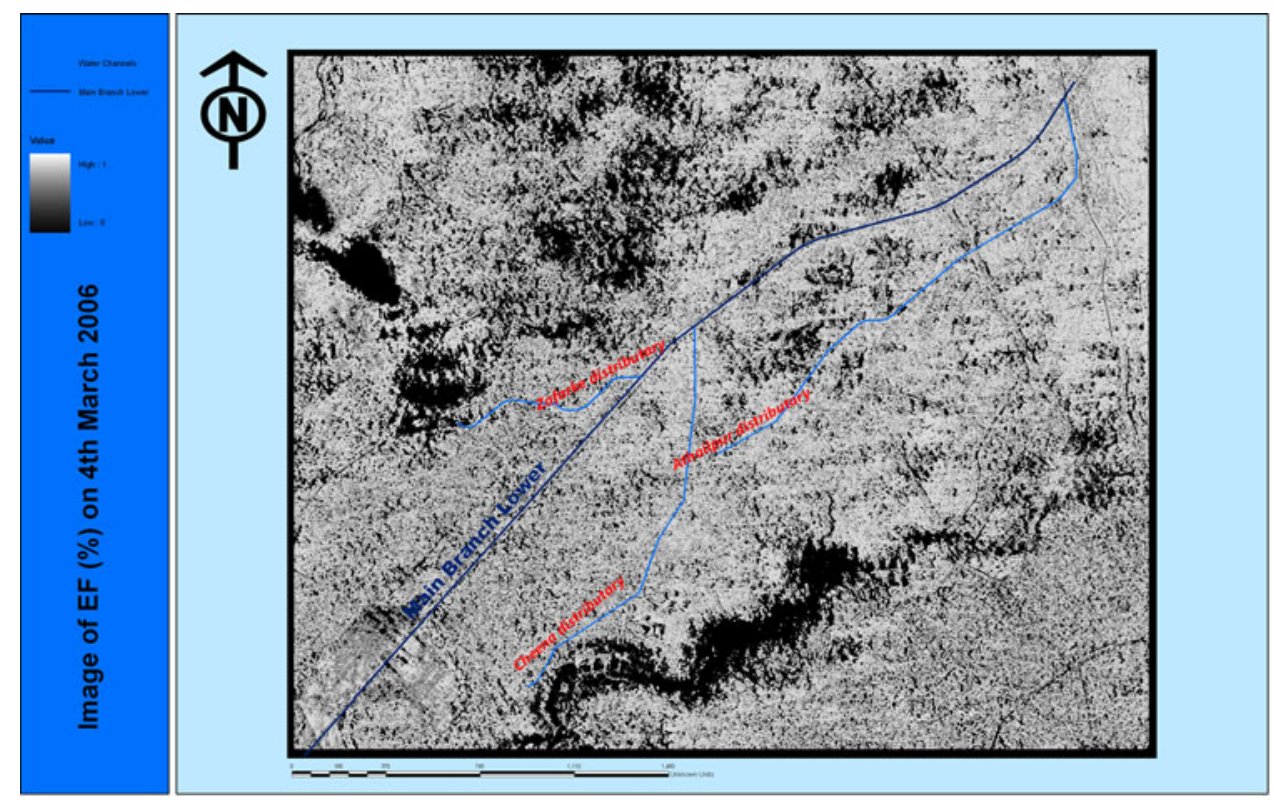
Fig. 3 Spatial variation of evaporative fraction $\mathrm{EF}(\%)$, on 5th April 2006

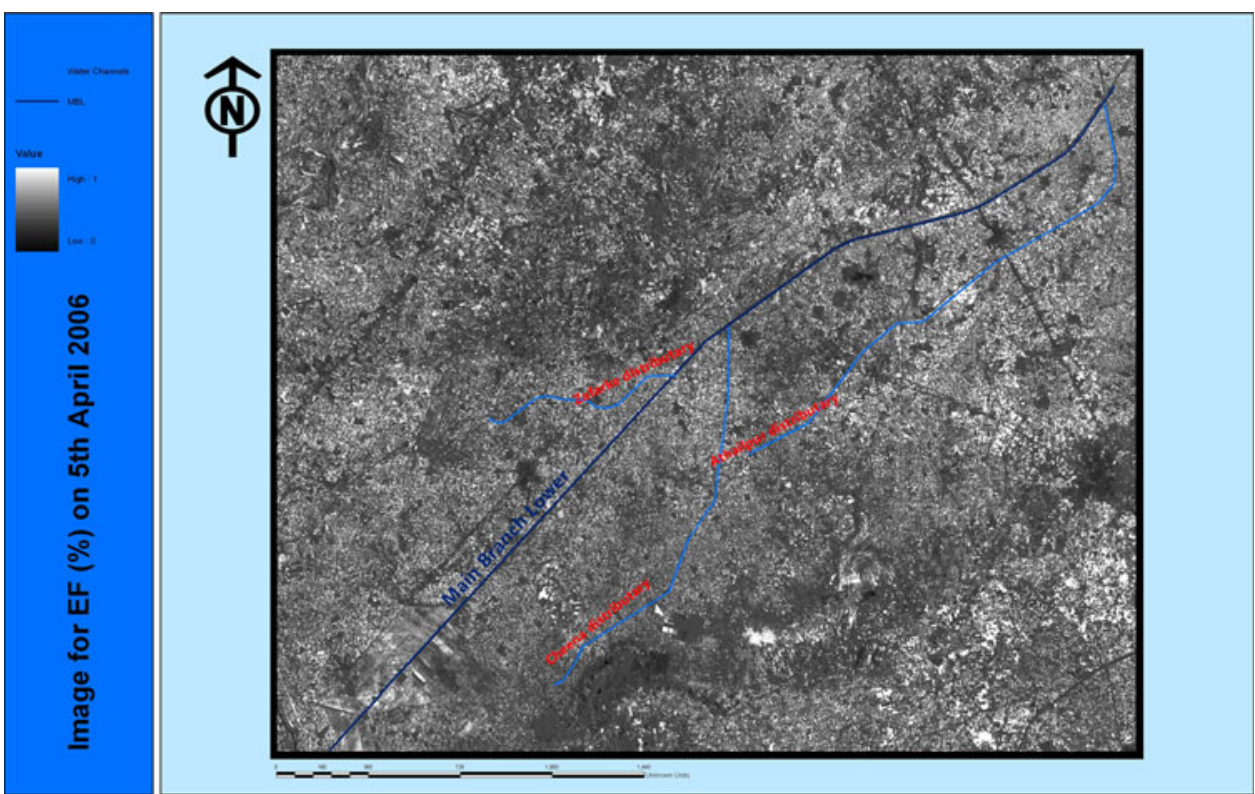

seen near the water channels, i.e., at heads of water courses. This indicates that significant energy is being used in ET by the crops which are dense and healthy. The black patches in these images indicate low ET due to poor crop stand and major portion of incoming radiations are converted into sensible heat flux. The ground truths confirmed the presence of dense and healthy crops in the upper reaches of the irrigation channels as compared to the lower reaches. Despite the spatial variation, temporal variation can also be seen in these images. Although the energy expressed as EF and/or instantaneous values of LE sufficiently shows the spatial variation (Figs. 2, 3), but for quantification of ET and assessment of irrigation water distribution over the entire day period, i.e., the 24-h values were computed for LE. Values of reference ET for both the days calculated and reported by Kalimullah et al. (2001) were used for validation purpose. These values of reference ET are $3.6 \mathrm{~mm} \mathrm{day}^{-1}$ on 4th March 2006 and $5.0 \mathrm{~mm}$ day $^{-1}$ on 5th April 2006 for this area.

The purpose of this research study is the assessment of spatial variation in canal water distribution; therefore, exact estimation of the ET values is not of much importance for this study. A separate study can be conducted to confirm these estimated values of ET by taking point measurements. Under this study it could not be done as it was beyond the scope of this study. The results depicted in the images (Figs. 2,3) are sufficient to assess the spatial variation in canal water distribution along the irrigation channels at their upper to lower reaches.

The ground truth data confirmed that $98 \%$ of the cropped area in the command of irrigation channels was under wheat crop when the images were acquired. Therefore, actual ET for wheat crop was calculated and the same is presented in Figs. 4 and 5 for 4th March and 5th April, respectively. Incorporating the ground data on cropped and non-cropped areas, it was noted that pixels having values of ET between 0.28 and $2.55 \mathrm{~mm} \mathrm{day}^{-1}$ on 4th March, and $0.20-2.80 \mathrm{~mm}^{\text {day }}{ }^{-1}$ on 5th April 2006 were under wheat crop. The pixels having values lower than these limits were either under bare soil or buildings or roads. Values of evapo(transpi)ration from noncropped areas is different on both the dates. The value of ET $\left(0.28 \mathrm{~mm} \mathrm{day}^{-1}\right)$ on 4 th March is higher than the value of ET $\left(0.20 \mathrm{~mm} \mathrm{day}^{-1}\right)$ on 5 th April. This is because more water is available in the root zone on 4th March than on 5th April. In April, bare soils (barren lands) become dry causing reduction in ET. On the other hand, upper limit of values of ET from cropped areas are higher on 5th April than on 4th March. It is in contradiction to ET trends from non-cropped areas where upper limit of evaporation is less in April than in March. This may be due to increase of temperatures. Similarly, distribution of percent area under different categories of cropped and noncropped area differs greatly on both the dates.

The values of ET as shown in Figs. 4 and 5 are in good agreement with reference ET (3.60 and $5.00 \mathrm{~mm} \mathrm{day}^{-1}$ ) and pan evaporation ( 3.8 and $6.9 \mathrm{~mm} \mathrm{day}^{-1}$ ) for 4th March and 5th April, respectively, as presented in (Table 1).

Figures 4 and 5 clearly indicate the spatial variation of crop ET which is an indication of spatial variation of canal irrigation supplies. From the above results it can be seen that the ET calculated by using remote sensing with the methodology presented here is in good agreement with the actual ET values. Thus, the approach discussed in this article can be used to compute ET using remote sensing data with reasonable accuracy.

A cluster of three watercourses each at the head, middle and tail of the three distributaries were selected for ground truths and areas of these three watercourses at each of the selected distributaries were cut from full images and were 
Fig. 4 Spatial Variation of $24 \mathrm{~h}$ crop ET $\left(\mathrm{mm} \mathrm{day}^{-1}\right)$ on 5 th April 2006
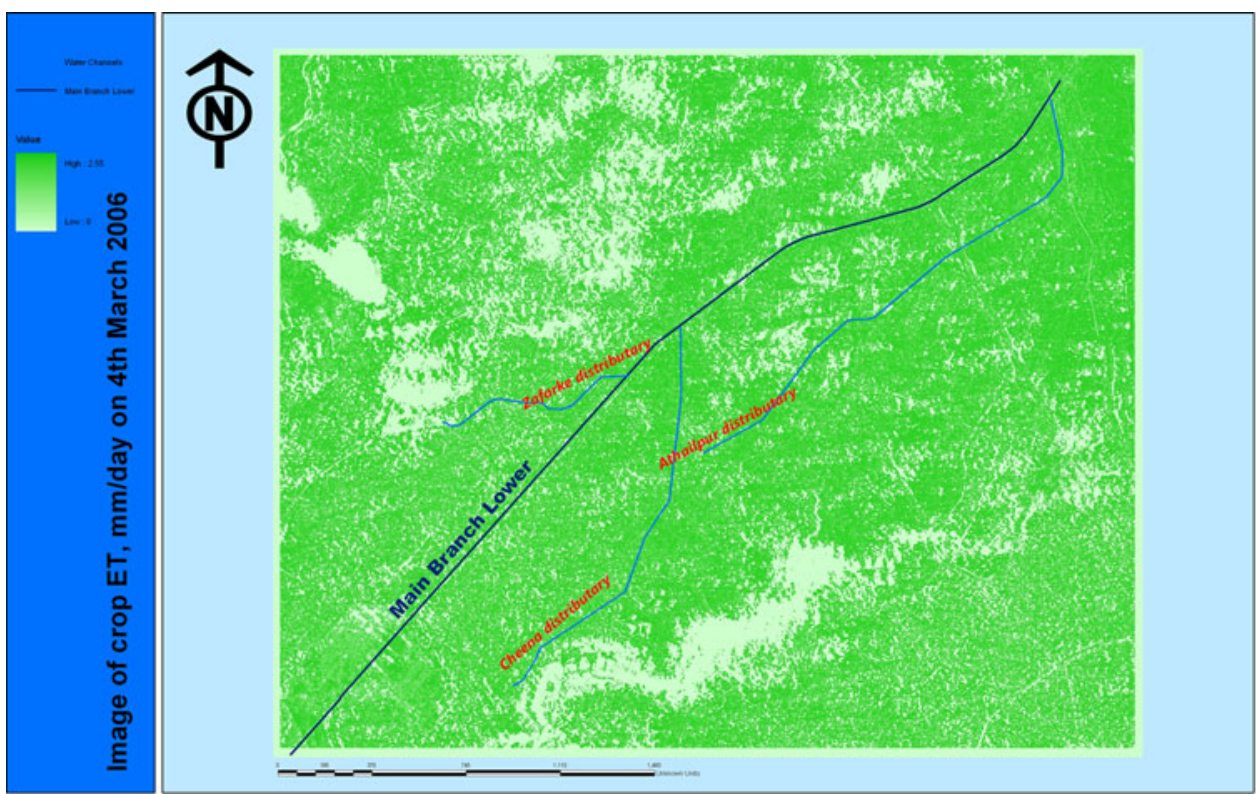

Fig. 5 Spatial Variation of $24 \mathrm{~h}$ crop ET $\left(\mathrm{mm} \mathrm{day}^{-1}\right)$ on 5 th April 2006

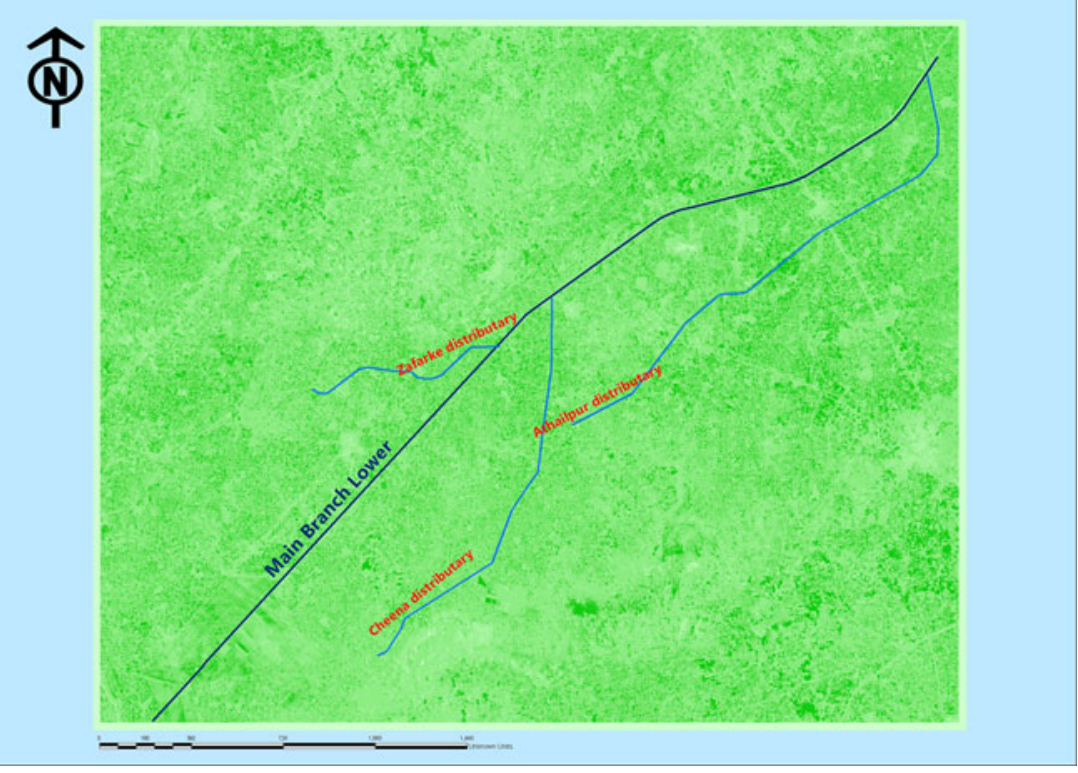

analyzed to find spatial variation in water distribution. Using ArcGIS software, classification of these images was done on the basis of three classes of ET values as given in Table 2.

Ground truth data revealed that values of ET in class I pertain to the areas under bare soil, buildings and roads. ET values above the ET of class I show the area under crops and it was split into two classes, i.e., below $60 \%$ of crop ET values in class II with consideration of crop under stress (poor crop) and above $60 \%$ of ET values under class III for the crop having no stress (healthy crops). Generally, water supply is considered to be satisfactory if $60 \%$ of the crop water requirement is fulfilled and below this crop is considered to be under stress. Percent of area under each
Table 2 Range of ET values under different classes of land use and water availability

\begin{tabular}{llll}
\hline Class & Description of area & \multicolumn{2}{c}{ Range of ET values $\left(\mathrm{mm} \mathrm{day}^{-1}\right)$} \\
\cline { 3 - 4 } & & 4th March 2006 & 5th April 2006 \\
\hline I & Uncultivated & $0.00-0.28$ & $0.00-0.20$ \\
II & Under stress & $0.28-1.67$ & $0.20-1.67$ \\
III & No stress & $1.67-2.55$ & $1.67-2.80$ \\
\hline
\end{tabular}

class was calculated by the in-built capability of ArcGIS software. This software performed it by counting the number of pixels falling under a particular class of ET and 
Table 3 Spatial variation of percentage area under different classes of ET with specified ranges of ET

\begin{tabular}{|c|c|c|c|c|c|c|c|}
\hline \multirow{3}{*}{$\begin{array}{l}\text { Name of } \\
\text { distributary }\end{array}$} & \multirow{3}{*}{$\begin{array}{l}\text { Water-course } \\
\text { location }\end{array}$} & \multicolumn{6}{|c|}{ Percentage area under given range of ET $\left(\mathrm{mm} \mathrm{day}^{-1}\right)$} \\
\hline & & \multicolumn{3}{|c|}{$\begin{array}{l}\text { On 4th March 2006, ET ranging } \\
\text { between }\end{array}$} & \multicolumn{3}{|c|}{$\begin{array}{l}\text { On 5th April 2006, ET ranging } \\
\text { between }\end{array}$} \\
\hline & & $<0.28$ & $0.28<1.67$ & $1.67<2.55$ & $<0.20$ & $0.20<1.67$ & $1.67<2.80$ \\
\hline \multirow[t]{3}{*}{ Athailpur } & Head & 7 & 18 & 75 & 5 & 75 & 20 \\
\hline & Middle & 12 & 19 & 69 & 10 & 78 & 12 \\
\hline & Tail & 17 & 20 & 63 & 13 & 82 & 5 \\
\hline \multirow[t]{3}{*}{ Cheena } & Head & 6 & 12 & 82 & 5 & 73 & 22 \\
\hline & Middle & 13 & 11 & 76 & 10 & 72 & 18 \\
\hline & Tail & 15 & 14 & 71 & 12 & 75 & 15 \\
\hline \multirow[t]{3}{*}{ Zafarke } & Head & 9 & 28 & 63 & 7 & 56 & 37 \\
\hline & Middle & 18 & 33 & 49 & 10 & 55 & 35 \\
\hline & Tail & 23 & 35 & 42 & 16 & 59 & 25 \\
\hline \multicolumn{2}{|c|}{ Range of percent area $(\%)$} & $6-23$ & $11-35$ & $42-82$ & $5-16$ & $55-82$ & $5-37$ \\
\hline
\end{tabular}

percentage of area under crop having particular value of ET was then calculated. Hence with the above classification of the area on the basis of crop ET, percent of areas falling under each of these three classes were calculated for both the periods. These calculations were also done for each of three clusters of watercourses at each of the three distributaries as given in Table 3 and presented in Figs. 6i-ix for 4th March 2006 and in Figs. 7i-ix for 5th April 2006.

The results presented in Table 3, show that 6-23\% of the area falls under class I on 4th March 2006 which

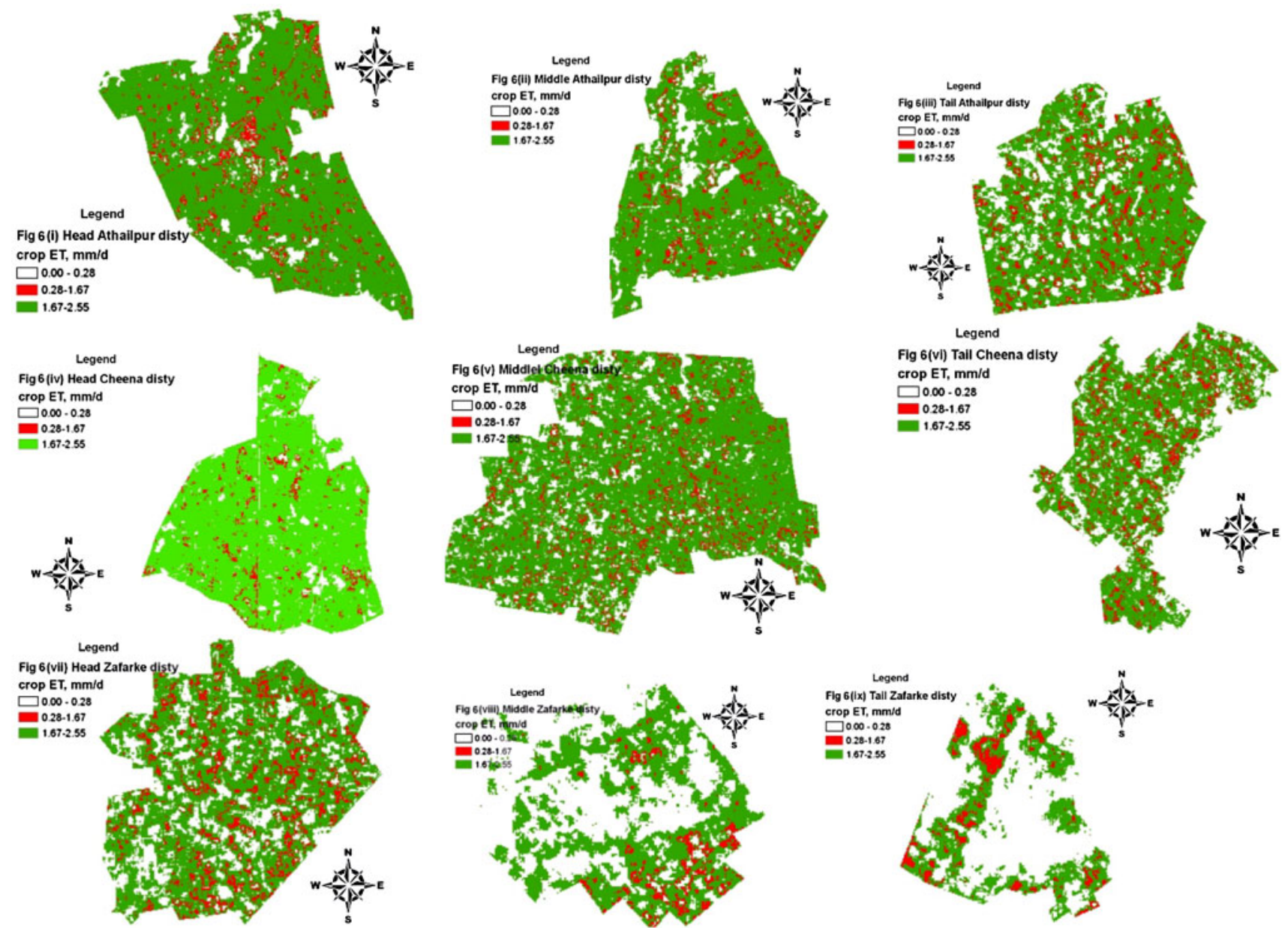

Fig. 6 (i to ix) Spatial variation of $24 \mathrm{~h}$ crop ET $\left(\mathrm{mm} \mathrm{day}^{-1}\right.$ ) along the selected watercourses on different distributaries on 4 th March 2006 

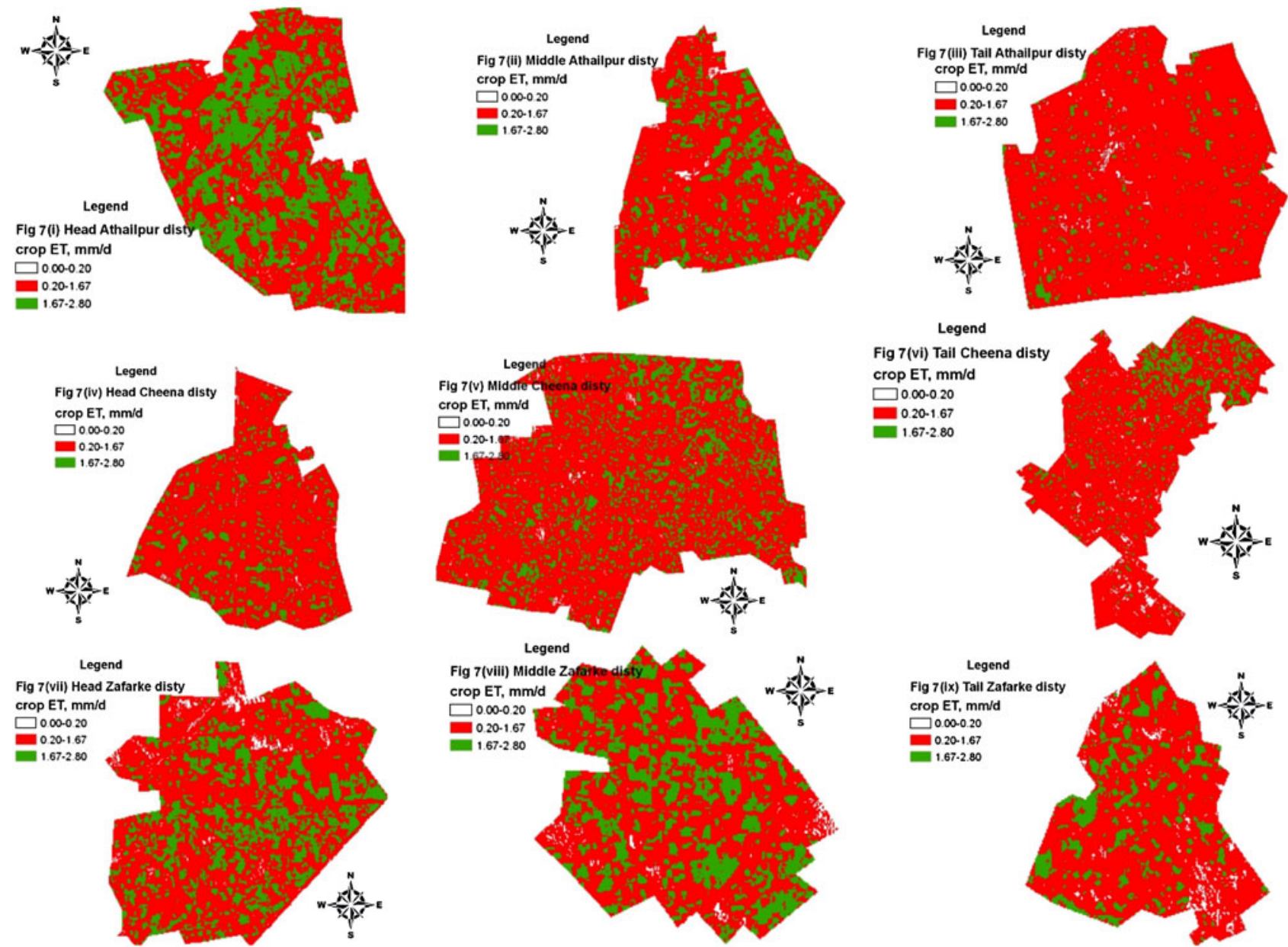

Fig. 7 (i to ix) Spatial variation of $24 \mathrm{~h}$ crop ET $\left(\mathrm{mm} \mathrm{day}^{-1}\right)$ along the selected watercourses on different distributries on 5 th April 2006

pertains to bare soil, roads and buildings, while this area reduces to $5-16 \%$ in April. There is a considerable change in percent of area during one month i.e. (4th March to 5th April) under this class which is mainly due to the reason that at this time, the crop stand was poor with limited number of tillers in start of March which became dense and mature in April. Specially, the higher percentage area under class I in March is observed in the command area of Zafarke distributary which is at the tail of the main canal. This shows that water is much scarce in the tail areas. The ground data and the image of April both confirm the presence of crop which was very poor in March and such cropped area falling under class I pertained to bare soil, roads and buildings. Similarly, it can be observed that on 4th March, 11-35\% of the area falls under class II and 42-82 \% area falls under class III with maximum crop ET as compared to percent area values on 5th April which is 55-82\% under class II and 5-37\% under class III. This is due to the reason that the wheat crop was lush green and frequently irrigated on March as compared to April. On 5th April percent area under class III with maximum ET has decreased much from the area of 4th March falling under this class, as the crop became mature and frequency of irrigation was also reduced.

From Table 3, the comparison of areas on the basis of their location shows that percent areas under class III (selected range of crop ET) for watercourses lying at the head, middle and tail of the distributaries (Athailpur, Cheena and Zafarke) emerging from the main canal decreased from head to tail of the system. It means water supply decreases downward of the system and spatial variation in irrigations water distribution can be clearly observed. This phenomenon is also notable in Figs. 8 and 9.

However, this variation is clearer in the month of March as compared to April when the crop was matured requiring no more irrigation. It indicates that the moisture stored in the root zone under the area at the head of the system is more as compared to downstream areas which is the evidence of more water availability near head of the system than the tail areas. Also along the main canal, the Athailpur distributary which is lying at the head has more percentage area under the selected range of ET as compared to the distributaries lying downstream. This phenomenon is more 
Fig. 8 Spatial variation of percent area under specified range of ET along watercourses on 4th March 2006

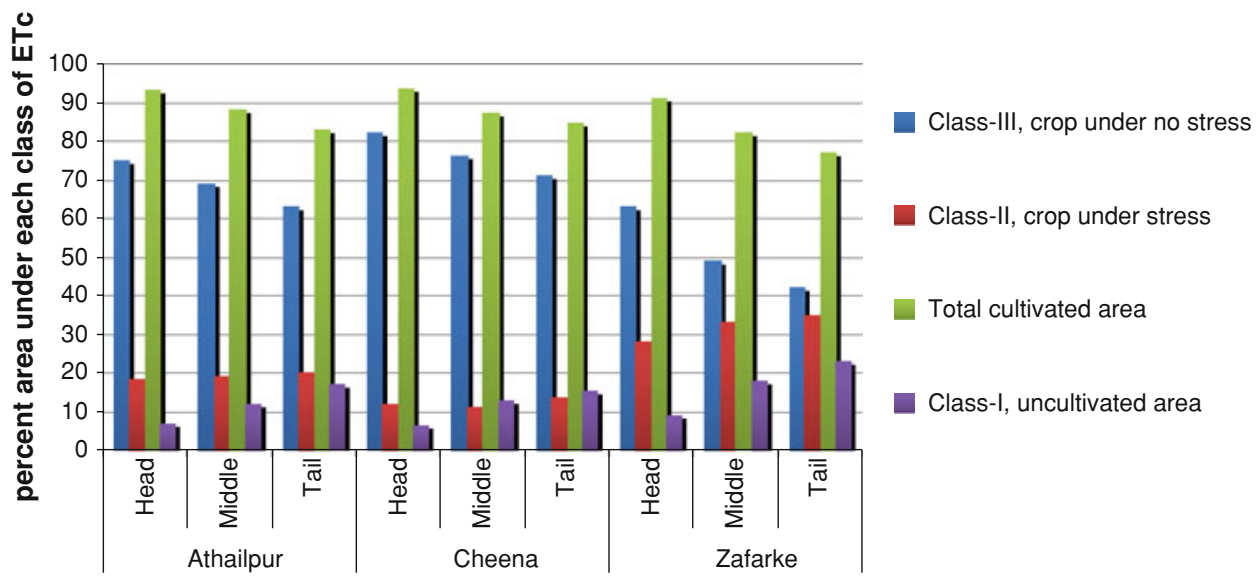

Location along the system
Fig. 9 Spatial variation of percent area under specified range of ET along watercourses on 5th April 2006

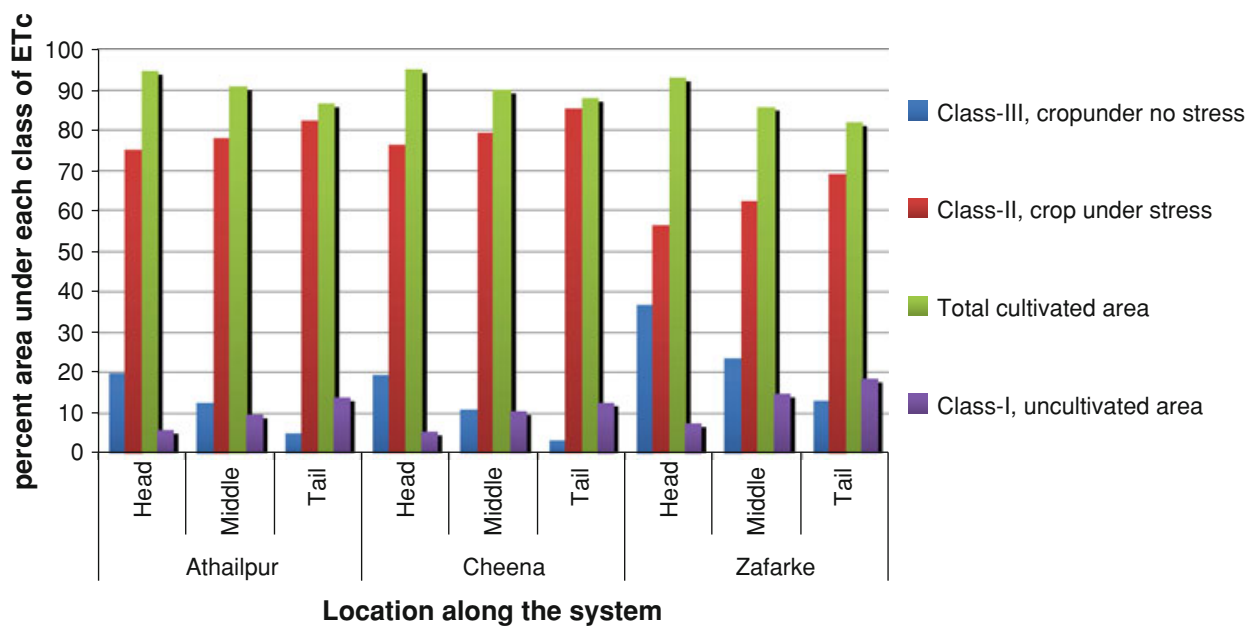

clear from the images of March, when frequent irrigations were applied.

Bar charts showing the variation in percent area under class I, II and III for all the selected areas are presented in Figs. 8 and 9 which show the variation of area under all three classes. However, class III having highest range of ET shows the variation with more clarity. Watercourses lying at the head have more area under this highest range of ET showing availability of more water than at the tail watercourses. Similarly, percentage areas under highest range of ET decreased in April due to maturity of the crop. These variations confirm the validity of the methodology proposed in this article.

\section{Conclusion}

Many studies have been conducted in the past for assessing performance of irrigation systems and equitable water distribution using point data. Several applications of remote sensing techniques have been developed during the last few decades, one of which is its application in studying the heat transfer phenomenon of the heat radiated by sun. In this research study, remote sensing data in Red- and NIR bands derived from ASTER satellite imageries was used to find NDVI values. Similarly, the thermal infrared spectrum was used to determine surface temperatures, which in combination with the measured air temperatures were used to calculate the sensible and the latent heat fluxes. These values of the fluxes were used in the energy balance equation to obtain evaporation fraction, EF and subsequently evapo(transpi)ration, ET. Hence, the ASTER satellite imageries were converted into images of EF and ET from which ET values on pixel-by-pixel basis were estimated. It is found that the ET values varied from zero to $2.55 \mathrm{~mm} \mathrm{day}^{-1}$ on 4th March 2006 and zero to $2.80 \mathrm{~mm} \mathrm{day}{ }^{-1}$ on 5th April 2006, respectively. Further classification of these ET images revealed that the maximum evaporation takes place from the water surface, i.e., canals and the minimum from the bare soil/buildings/roads. It was also found that the pixels lying at the heads or near the irrigation channels have high values of ET as compared to the pixels lying at the tail ends or away from the system. Similarly, percentage of the cropped area having higher ET values is more near the system as compared to the location of tail ends or away from the system. This spatial variation of ET is due to 
the spatial variability in canal water distribution. A general conclusion can be drawn from the results of this study that fields at the head of the canals/distributaries are receiving comparatively more canal water as compared to the fields located towards tail ends of the system. This variation has caused water scarcity, degradation of land and environment, poor socio-economic conditions and poverty of the farmers in tail reaches of the irrigation channels.

Acknowledgments Thanks are extended to Higher Education Commission of Pakistan who provided financial support to carry out this research study through Indigenous Scholarship package III.

\section{References}

Abdullah KB (2006) Use of water and land for food security and environmental sustainability. Irrig Drain J ICID 55(3):219-222

Akbari M, Tomanian N, Droogers P, Bastiaanssen W, Gieske A (2007) Monitoring irrigation performance in Esfahan, Iran, using NOAA satellite imagery. J Hydrol 212(213):198-212

Bastiaanssen WGM (2000) SEBAL-based sensible and latent heat fluxes in the irrigated Gediz basin, Turkey. J Hydrol 229:87-100

Bastiaanssen WGM, Menenti M, Feddes RA, Holtslag AAM (1998) A remote sensing surface energy balance algorithm for land (SEBAL)-1. Formulation. J Hydrol 212(213):198-212

Brutsaert WH (1975) On a derivable formula from long wave radiation from clear skies. Water Resour Res 11:742-744

Brutsaert W, Chen D (1996) Diurnal variation of surface fluxes during thorough drying (or severe drought) of natural prairie. Water Resour Res 32(7):2013-2019

Carlson TN, Dodd JK, Benjamin SG, Cooper JN et al (1981) Satellite estimation of the surface energy balance, moisture availability and thermal inertia. J Appl Meteorol 20:67-87

Carlson TN, Capehart WJ, Gillies RR et al (1995) A new look at the simplified method for remote sensing of daily evapotranspiration. Remote Sens Environ 49:264-274

Chavez P (1996) Image-based atmospheric correction-revisited and improved. Photogramm Eng Remote Sens 62:1025-1036

Crago RD (1996) Conservation and variability of the evaporative fraction during the day time. J Hydrol 180:173-194

Das AK, Iqbal M (1987) A simplified technique to compute spectral atmospheric radiation. Solar Energy 39(2)

Droogers P, Bastiaanssen WGM (2002) Irrigation performance using hydrological and remote sensing modeling. J Irrig Drain 128(1):11-18

Gillespie AR, Rokugawa S, Hook SJ, Matsunga T, Kahle AB (1996) Temperature/emissivity separation algorithm theoretical basis document, Ver. 2.3, NASA contract NAS5-31372

Gillespie A, Rokugawa S, Matsunaga T, Cothern JS, Hook S, Kahle AB (1998) A temperature and emissivity separation algorithm for Advanced Spaceborne Thermal Emission and Reflection Radiometer (ASTER) images. IEEE Trans Geosci Remote Sens 36(4):1113-1126

Gurney RJ, Hall DK et al (1983) Satellite-derived surface energy balance estimates in the Alaskan sub-arctic. J Clim Appl Meteorol 22:115-125

Hall FG, Huemmrich K, Goetz SJ, Sellers PJ, Nickerson JE (1992) Satellite remote sensing of surface energy balance: success, failure and unresolved issues in FIFE. J Geophys Res 97(D17):19061-19090

Iqbal M (1983) An introduction to solar radiation. Academic Press, Toronto
Jackson RD (1985) Evaluating evapotrans-piration at local and regional scales. Proc IEEE 73:1086-1095

Jackson RD, Hatfield JL, Reginato RJ, Idso SB, Pinter JB Jr et al (1983) Estimation of daily evapotranspiration from one time of day measurements. Agric Water Manag 7:351-362

Kalimullah M, Habib Z, Muhammad S (2001) Spatial distribution of reference and reference evapotranspiration across the Indus basin irrigation systems. International Water Management Institute (IWMI working paper 24)

Kustas WP, Perry EM, Doraiswamy PC, Moran MS et al (1994) Using satellite remote sensing to extrapolate evapotranspiration estimates in time and space over a semi-arid range land basin. Remote Sens Environ 49:275-286

Latif M (2007) Spatial productivity along a canal irrigation system in Pakistan. Irrig Drain J 56(5):509-521 (IRD 320, International Commission on Irrigation and Drainage (ICID), John Wiley \& Sons (Wiley InterScience), U.K., pp. 509-521, An internationally abstracted journal, ISSN: 1531-0353)

Latif M, Ahmad MZ (2007) Integrated water resources management for sustainable development in a selected canal command in Pakistan. CEWRE/publications/214, research report No. 26

Lu D, Mausel P, Brondizio E, Moran E (2002) Assessment of atmospheric correction methods for Landsat TM data applicable to Amazon basin LBA research. Int J Remote Sens 23:2651-2671

Milder JC (2008) ASTER processing method. Department of Natural Resources, Cornell University, Ithaca

Moran MS (1990) A satellite based approach for evaluation of the spatial distribution of evapotranspiration from agricultural lands. $\mathrm{PhD}$ dissertation, University of Arizona, Tucson (abstract)

Moran MS, Jackson RD et al (1991) Assessing the spatial distribution of evapotranspiration using remotely sensed inputs. J Environ Qual 20:525-537

Norman JM, Kustas WP, Humes KS et al (1995) Source approach for estimating soil and vegetation energy fluxes from observation of directional radiometric surface temperature. Agric For Meteorol 77:263-293

Price JC (1982) Estimation of regional scale evapotranspiration through analysis of satellite thermal infrared data. IEEE Trans Geosci Remote Sens GE-20:286-292

Schmugge TJ, Kusta WP, Humes KS et al (1998) Monitoring land surface fluxes using ASTER observations. IEEE Trans Geosci Remote Sens 36(5):1421-1430

Shuttleworth WJ, Gurney RJ, Hsu AY, Ormsby JP et al (1989) FIFE: the variation in energy partitioning at surface flux sites. IAHS Red Book Series No. 186:67-74

Smith AMS (2007) How to convert ASTER radiance values to reflectance: an online guide. College of Natural Resources, University Idaho

Sugita M, Brutsaert W (1991) Daily evaporation over a region from lower boundary layer profiles. Water Resour Res 27:747-752

Taconet O, Bernard R, Vidal-Madjar D (1986) Evapotranspiration over an agricultural region using a surface flux/temperature model based on NOAA-AVHRR data. J Clim Appl Meteorol 25:284-307

Thom AS, Oliver HR et al (1977) On Penman's equation for estimating regional evaporation. Q J R Meteorol Soc 103:345-357

Tomanian A, Gieske A, Akbari M (2004) Irrigated area determination by NDVI-Landsat upscaling techniques, Zayandeh River Basin, Esfahan. Iran Int J Remote Sens 15(22):4945-4960

Van De Griend AA, Owe M (1993) On the relationship between thermal emissivity and the normalized difference vegetation index for natural surfaces. Int J Remote Sens 14(6):1119-1131

Yamaguchi Y, Kahle AB, Tsu H, Kawakami T, Pniel M (1998) Overview of Advanced Spaceborne Thermal Emission and Reflection Radiometer (ASTER). IEEE Trans Geosci Remote Sens 36:1062 